\title{
Sensitivity analysis of several operational parameters on gas temperature deviation in a tangential firing boiler
}

\author{
Cong $\mathrm{Yu}^{1, *}$, Haiquan $\mathrm{Yu}^{2}$, Wenpeng $\mathrm{Hu}^{3}$, and Hanlin $\mathrm{Wu}^{1}$ \\ ${ }^{1}$ Jianghan University, School of Intelligent Manufacturing, 430056 Wuhan, P.R. China \\ ${ }^{2}$ Southeast University, School of Energy and Environment, 210096 Nanjing, P.R. China \\ ${ }^{3}$ Wuhan Hengxintai Oil Production Equipment Manufacturing Co., Ltd., 430299 Wuhan, P.R. China
}

\begin{abstract}
In this work, an integrated numerical model combining combustion and fluid heating was established for a $660 \mathrm{MW}$ coal-fired boiler. To validate the accuracy of the developed model, related experiment was also conducted, and shows that the relative errors (REs) of several predicted parameters on both flue-gas side and water-steam side of the boiler are less than $7 \%$, which meets the requirement of analysis. The results indicate that the effect of SOFA tilt angle on gas temperature deviation (GTD) is greatest, and that of SOFA's proportion follows; while GTD presents a smallest sensitivity to the concentration of $\mathrm{O}_{2}$. This is because $\mathrm{O}_{2}$ concentration mainly affects the average value of the gas temperature, but barely changes its distribution. By contrast, altering SOFA's tilt angle and its proportion directly varies the shape, location, and area of the high-temperature and low-temperature regions at the entrance profile of the horizontal crossover pass, so these two factors play a more important role in the variation of GTD.
\end{abstract}

\section{Introduction}

During the past decades, to improve the thermal efficiency of the coal-fired power plants, utility boilers have been developed towards a larger capacity and a higher steam parameters. In this context, the fluid inside the tubes can be heated to a supercritical or even ultrasupercritical pressure, and the steam temperature of some boilers can reach as high as $700{ }^{\circ} \mathrm{C}$ [1]. However, once overheating failure occurs among these tubes, not only would it waste the fuel and energy, but also the leaked steam with high momentum and temperature could impact the adjacent tubes, causing a secondary damage. Therefore, it is necessary to guarantee the security of the steam tube system during the process of the electricity generation.

Among all heat exchangers, final superheaters and reheaters receive the greatest attention, because their tube walls attain the highest temperatures in the boiler [2]. It has been suggested that the tube overheating problem of these high-temperature heating surfaces results from an unexpected gas temperature deviation (GTD) in the horizontal crossover pass of the boiler [34]. In recent years, several researchers [5-8] have paid attention to revealing the causes and characteristics of this deviation. Liu [5] found that the residual swirl at the furnace exit plays an important part in generating GTD. By retrofitting the boiler's structure, Tan et al [6] optimized the in-furnace flow field and successfully alleviated such a temperature deviation. In addition, the effects of several boiler's settings such as the opposing tangential angle of the air jets [7] and the vertical burner tilt angle [8] on GTD have also been studied. However, few studies have conducted a sensitivity analysis to compare the degrees and mechanisms that these factors act on GTD.

In this work, a simulation which combines coal combustion and fluid heating was carried out for a 660 MW tangential firing boiler, and related experiment were performed for the model validation. Based on the model, the effects of $\mathrm{O}_{2}$ concentration, separated over-fire air (SOFA) tilt angle, and SOFA's proportion on GTD were further discussed.

\section{In situ measurements}

\subsection{Boiler description}

As shown in Fig. 1, the boiler considered in the present work is a $660 \mathrm{MW}$ supercritical pulverized coal-fired boiler, which has a furnace equipped with a tangentially fired system. A set of low-NOx concentric firing burners were installed in the furnace, composed of six groups of primary air nozzles, six groups of secondary air nozzles, two groups of CCOFA nozzles and five groups of SOFA nozzles.

\subsection{Operational condition and measurements}

To validate the numerical model of the boiler, an experiment at the full load condition was conducted, and

\footnotetext{
* Corresponding author: congy@seu.edu.cn
} 
several key parameters were measured, including the concentrations of $\mathrm{O}_{2}$ and $\mathrm{CO}$ after the economizer, the gas temperature at the exit of the final reheater $(\mathrm{RH})$, and the pressure, temperature and mass flow rate at the inlet and outlet of four high-temperature heat exchangers, namely the division superheater $(\mathrm{SH})$, the platen $\mathrm{SH}$, the final $\mathrm{RH}$, and the final $\mathrm{SH}$.

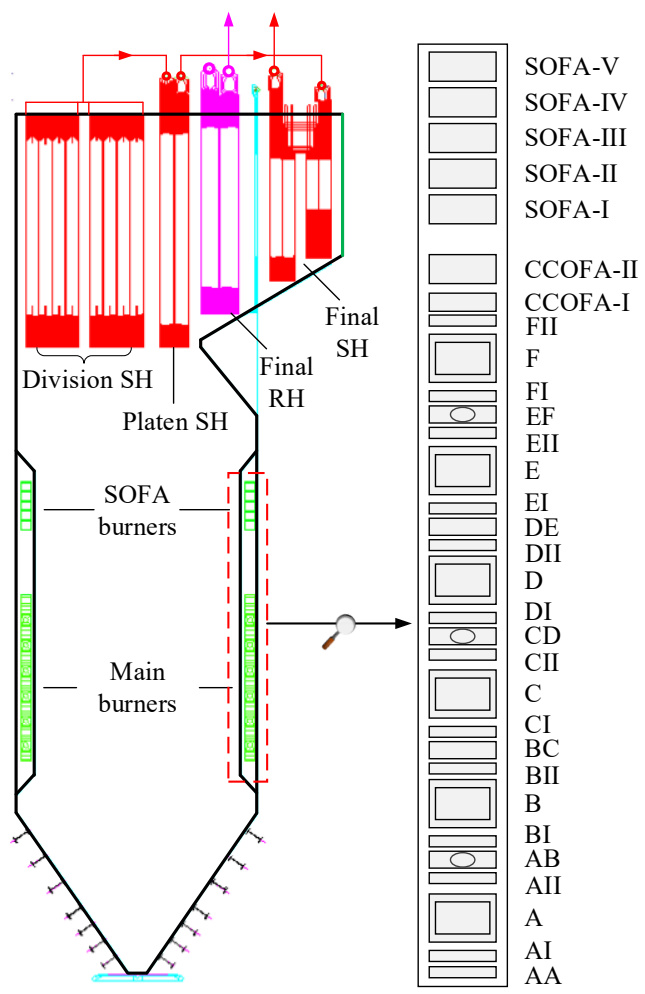

Fig. 1. Schematics of the furnace and burners.

Table. 1 provides the coal properties during the experiment. Apart from that, the value of pulverized-coal finenesses R90 and R200 were also measured as 33.6\% and $3.3 \%$, respectively. Thus, the distribution of the coal particles can be estimated, which follows the RosinRammler ruler with a mean diameter of $61 \mu \mathrm{m}$ and a spread parameter of 1.15 .

Table 1. Coal properties during the experiment.

\begin{tabular}{|c|c|c|c|c|}
\hline \multicolumn{4}{|c|}{ Proximate Analysis $\left(\mathrm{ar}^{1}, \mathrm{wt} . \%\right)$} & \multirow{2}{*}{$\begin{array}{c}Q_{\text {net, ar }} \\
(\mathrm{MJ} / \mathrm{kg})\end{array}$} \\
\hline Moisture & Volatile & Ash & $\begin{array}{l}\text { Fixed } \\
\text { carbon }\end{array}$ & \\
\hline 7.48 & 24.34 & 23.73 & 44.45 & 22.447 \\
\hline \multicolumn{5}{|c|}{ Ultimate Analysis ( $\mathrm{ar}^{1}$, wt. \%) } \\
\hline $\mathrm{C}$ & $\mathrm{H}$ & $\mathrm{O}$ & $\mathrm{N}$ & $\mathrm{S}$ \\
\hline 56.4 & 3.18 & 8.01 & 0.64 & 0.55 \\
\hline
\end{tabular}

${ }^{1}$ As received basis

The experiment was carried out at the full load of $660 \mathrm{MW}$. In this case, the total mass flow rate of the pulverized coal was $282 \mathrm{t} / \mathrm{h}$, which was equally distributed to the mills A to F. The air had a total mass flow rate of $2360 \mathrm{t} / \mathrm{h}$, of which $27.4 \%$ was the primary air with a temperature of $351 \mathrm{~K}$ and $72.6 \%$ was the secondary air with a temperature of $581 \mathrm{~K}$. Five layers of SOFA took up $26 \%$ of the total air and had a same vertical tilt angle of $-12^{\circ}$. For the water-steam cycle, the mass flow rates of the $\mathrm{SH}$ and the $\mathrm{RH}$ were $1955 \mathrm{t} / \mathrm{h}$ and $1632 \mathrm{t} / \mathrm{h}$, respectively. At the inlet of the water wall heaters, the division $\mathrm{SH}$, and the final $\mathrm{RH}$, the temperature and pressure of the fluid were separately $596 \mathrm{~K} / 26.9 \mathrm{MPa}, 687 \mathrm{~K} / 25.9 \mathrm{MPa}$, and $733 \mathrm{~K} / 4.4 \mathrm{MPa}$.

\section{Numerical modelling}

\subsection{Mathematical models}

The mathematical models are presented in Table. 2. These models were applied to describe the complex physical and chemical processes within the furnace, and considered the conjugate heat transfer in the tubes of the water wall heaters, the division $\mathrm{SH}$, the platen $\mathrm{SH}$, the final $\mathrm{RH}$, and the final $\mathrm{SH}$. In the present work, the models related to coal combustion was solved using Fluent 14.5, while the thermal hydraulic model inside the tubes was numerical simulated via MATLAB coding. More detailed descriptions of these models, the modelling parameters in them, and the coupled methods have been provided in our previous work [4].

Table 2. Mathematical models.

\begin{tabular}{cc}
\hline $\begin{array}{c}\text { Physical and chemical } \\
\text { processes }\end{array}$ & Models used in this work \\
\hline Turbulent flow & Realizable k- $\varepsilon$ model \\
Coal particle transport & Discrete phase model (DPM) \\
Coal devolatilization & Two competing rate model \\
Gaseous combustion & Mixture fraction/PDF model \\
Char oxidation & Kinetics/diffusion limit rate model \\
Radiation & P-1 model \\
Fluid heating & Thermal hydraulic model \\
\hline
\end{tabular}

\subsection{Modelling cases and boundary conditions}

In this study, 8 cases were modelled. Case 1 was conducted for validation and had the same operational conditions with that of the experiment, in which the $\mathrm{O}_{2}$ molar fraction, the SOFA tilt angle, and the proportion of SOFA were $2.9 \%,-12^{\circ}$, and $26 \%$, respectively. To further investigate the effects of these three parameters, Case 2 to Case 8 were designed. Case 2, Case 3, and Case 4 set the SOFA tilt angle to $+30^{\circ}, 0^{\circ}$, and $+20^{\circ}$, respectively, and remain the other boiler settings identical to those in Case 1. In addition, on the basis of Case 4, Case 5 and Case 6 set the concentration of $\mathrm{O}_{2}$ to $2 \%$ and $3.5 \%$, respectively; while Case 7 and Case 9 change the proportion of SOFA to $15 \%$ and $35 \%$, respectively.

\section{Results and discussion}

\subsection{Validation}

Table. 3 shows some key operational parameters on both flue-gas side and water-steam side of the boiler. It can be seen that the predicted data from the CFD modelling and 
the experimental results are close. The relative errors (REs) of all the parameters are less than $7 \%$, which means the accuracy of the developed model is acceptable and this model can be used for the following analyses.

Table 3. Results from CFD modelling and experiment.

\begin{tabular}{ccc}
\hline Parameters & CFD & test \\
\hline Gas temperature/ K & 962 & 1027 \\
$\mathrm{O}_{2}$ molar fraction/ \% & 2.92 & 2.89 \\
CO molar fraction/ ppm & 575 & 593 \\
Heat absorption of division SH/ MW & 140.3 & 146.1 \\
Heat absorption of platen SH/ MW & 105.6 & 109.7 \\
Heat absorption of Final RH/ MW & 109.5 & 107.3 \\
Heat absorption of Final SH/ MW & 109.3 & 113.4 \\
\hline
\end{tabular}

\subsection{Causes of gas temperature deviation}

As shown in the Fig. 2, the pulverized coal and air were injected into the furnace, combusting and forming a counter-clockwise fire ball, which results in a residual swirling flow at the furnace exit. Thus, on the Crosssection P1, the velocity on the left side is higher than that on the right side. This further affects the distribution of gas temperature. A higher local velocity means the hot flue gas releases less heat in this place, namely at the left part of the upper furnace, the division $\mathrm{SH}$ and platen $\mathrm{SH}$ absorb less heat. Therefore, on the P1 plane, the gas temperature on the left side is also higher than that on
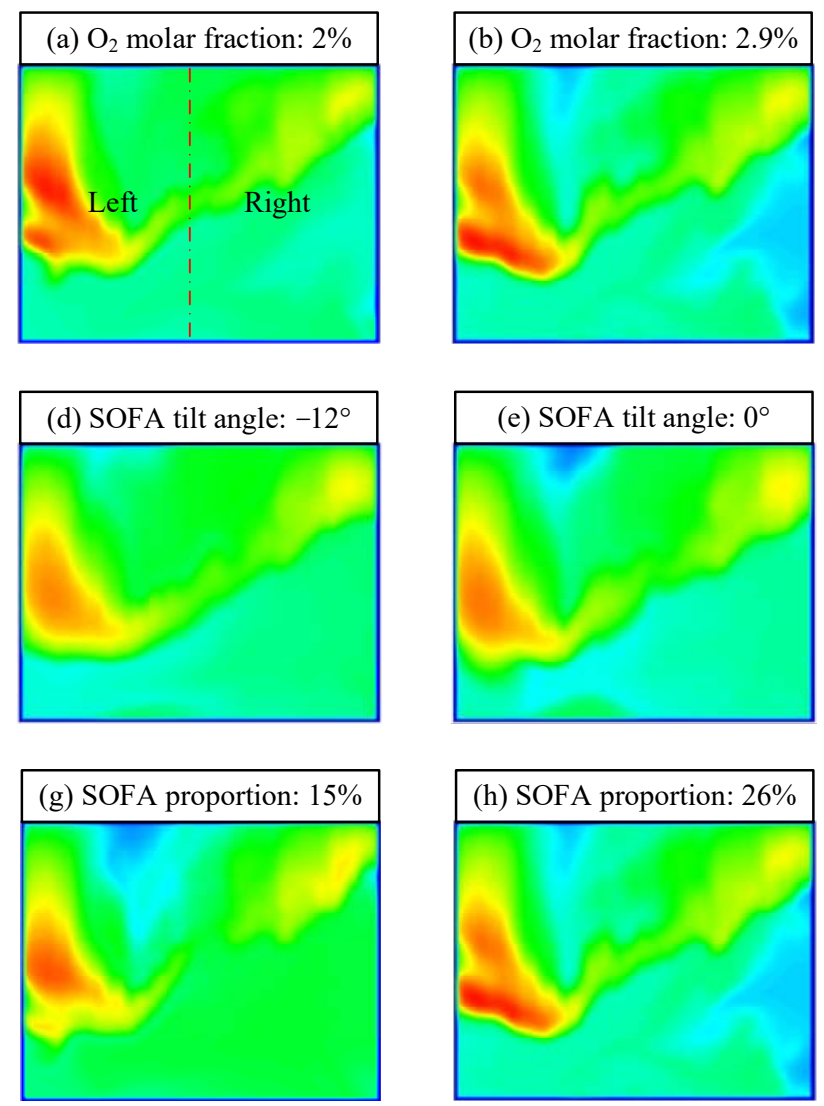

the right side, generating a GTD at the entrance of the horizonal crossover pass.

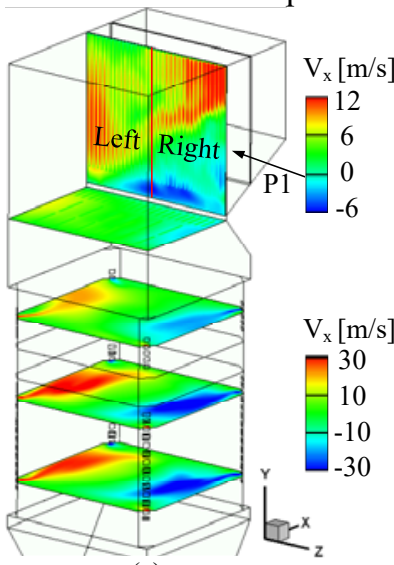

(a)

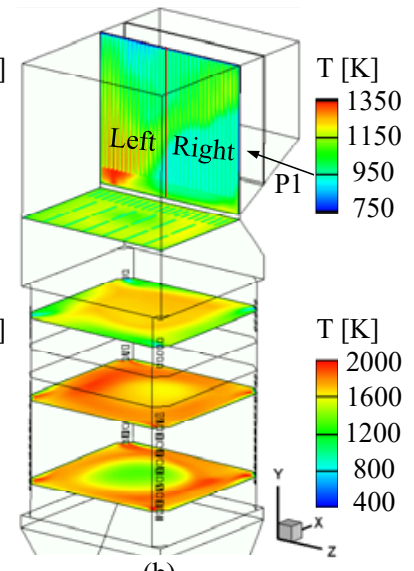

(b)
Fig. 2. Distributions of gas velocity and temperature on different planes from Case 1.

\subsection{Effects of $\mathrm{O}_{2}$ and SOFA on gas temperature deviation}

Fig. 3 shows the gas temperature distributions on plane 1, which is the entrance profile of the final $\mathrm{RH}$ and $\mathrm{SH}$. To perform a further quantitative analysis of GTD on this plane, Eq. 1 was defined as following:

$$
T_{\text {dev }}=T_{\text {ave,left }}-T_{\text {ave,right }}
$$

where $T_{\text {ave,left }}$ and $T_{\text {ave,right }}$ are the gas average temperature in the left and right parts on the P1 plane, respectively.
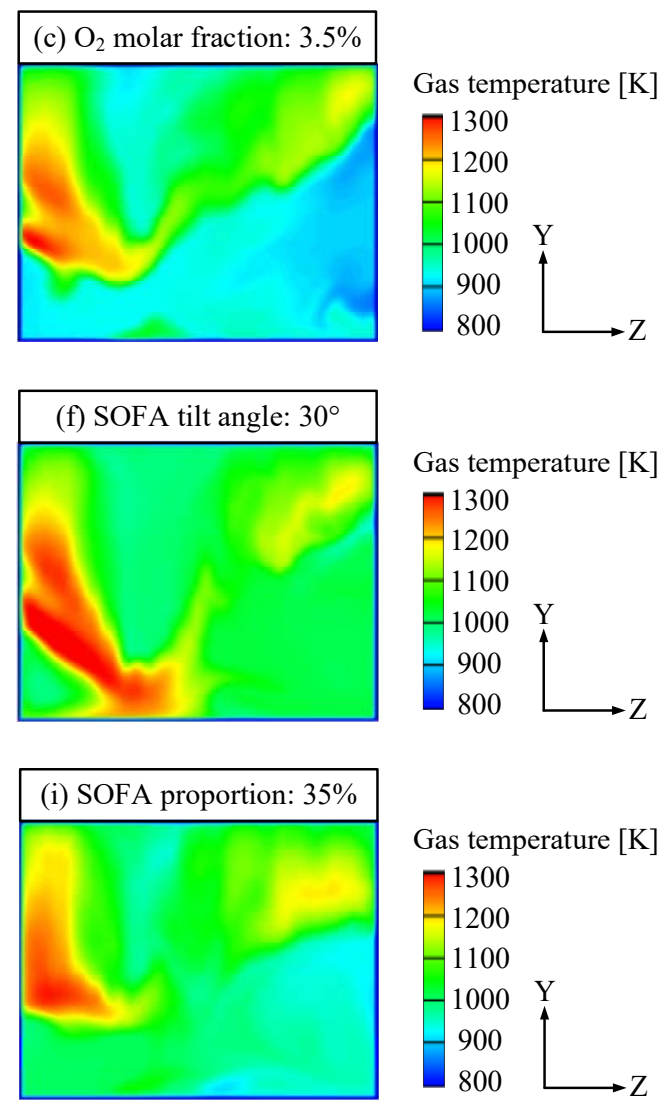

Fig. 3. Gas temperature distributions on plane 1 at different operational conditions. 
As shown in Fig. 4, when the concentration of $\mathrm{O}_{2}$, the SOFA tilt angle, and the proportion of SOFA increase within their regular operational intervals, the maximal differences of $T_{\mathrm{dev}}$ are separately $14 \mathrm{~K}, 29 \mathrm{~K}$, and $53 \mathrm{~K}$, which indicates that the proportion of SOFA has the greatest influence on GTD, and the effect of SOFA tilt angle follows; while this temperature deviation presents a smallest sensitivity to the $\mathrm{O}_{2}$ concentration.

It is found from Fig. 3(a) to Fig. 3(c) that, as the boiler operated at different $\mathrm{O}_{2}$ contents, the temperature distributions on the $\mathrm{P} 1$ plane are quite similar, which means that the shape, location, and area of the hightemperature and low-temperature regions show few differences. When adjusting the $\mathrm{O}_{2}$ concentration from $2 \%$ to $3 \%$ and $3.5 \%$, the gas average temperature on the left side of P1 separately dropped from $1059 \mathrm{~K}$ to $1043 \mathrm{~K}$ and $1038 \mathrm{~K}$, and that on the right side separately declined from $1017 \mathrm{~K}$ to $1000 \mathrm{~K}$ and $981 \mathrm{~K}$. This unbalanced decreases in gas temperature of the two parts cause the variations of GTD. By contrast, as shown from Fig. 3(d) to Fig. 3(i), altering SOFA, namely its tilt angle and proportion, directly changes the distribution of the gas temperature on the $\mathrm{P} 1$ plane. This is because, by determining the ratio of the air in the main stream to the air with an opposing tangential angle, SOFA settings can induce a different distribution of momentum within the furnace, so have a greater effect on GTD.
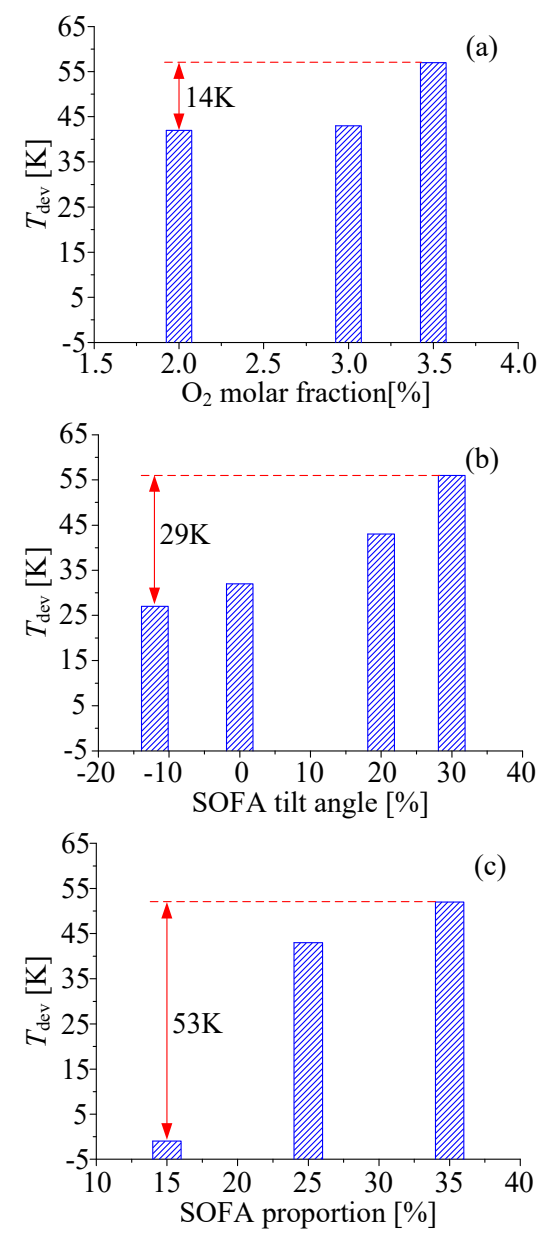

Fig. 4. Gas temperature deviations on plane 1 at different operational conditions.

\section{Conclusion}

In this work, an integrated numerical model was established for a $660 \mathrm{MW}$ tangential firing boiler, and related experiment was also conducted for the model validation. Based on this model, the effects of the $\mathrm{O}_{2}$ concentration, the SOFA tilt angle, and the proportion of SOFA on GTD were compared. The main conclusions can be drawn as follows:

(1) The effects of SOFA's tilt angle on GTD is the greatest, and that of its proportion follows; while GTD presents a smallest sensitivity to the $\mathrm{O}_{2}$ concentration.

(2) The way that $\mathrm{O}_{2}$ concentration affects GTD is by producing an unbalanced temperature variations on both sides of the P1 plane, but rarely changing the distribution of temperature.

(3) Altering SOFA's tilt angle or its proportion directly change the shape, location, and area of the hightemperature and low-temperature regions on the P1 plane, so these two factors show a greater effect on the variations of GTD.

(4) SOFA is an important factor both in changing the value of GTD and reducing $\mathrm{NO}_{\mathrm{x}}$ emission, so it needs to take a comprehensive account for this when doing combustion optimization.

\section{References}

1. C. Schuhbauer, M. Angerer, H. Spliethoff, F. Kluger, H. Tschaffon. Fuel 122, 149-163 (2014).

2. V. Maakala, M. Jarvinen, V. Vuorinen. Energy 160, 361-377 (2018).

3. G.W. Tang, B. Wu, K. Johnson, A. Kirk, D. Fu, C.Q. Zhou. Appl. Them. Eng. 102, 261-271 (2016).

4. C. Yu, W. Xiong, H. Ma, J.X Zhou, F.Q. Si, X.M. Jiang, X.W. Fang. Appl. Them. Eng. 154, 87-101 (2019).

5. Y.C. Liu, W.D. Fan, M.Z. Wu. Appl. Them. Eng. 110, 553-563 (2017).

6. P. Tan, Q.Y. Fang, S.N. Zhao, C.G. Yin, C. Zhang, H.B. Zhao. Appl. Them. Eng. 139, 135-143 (2018).

7. Y.G. Zhou, M.C. Zhang, T.M. Xu, S.E. Hui. Energy Fuels 23, 5375-5382 (2009).

8. P. Tan, D.F. Tian, Q.Y. Fang, L. Ma, C. Zhang, G. Chen, L.J. Zhong, H.G. Zhang. Fuel 196, 314-324 (2017). 